\title{
Laço Conjugal e Pós-Modernidade: Algumas Considerações Éticas
}

\author{
Maxia eAngélica Caxrexas \\ Psicanalista
}

\section{1}

rata-se, neste trabalho, de uma abordagem das manifestações no laço conjugal do discurso da pós-modernidade, fruto de uma mudança epistemológica que desconsidera a causa e seus efeitos para se centrar na ação eficiente, produto. ra de mercadorias e instrumentos entre os quais o próprio homem.

Corresponde a outra maneira de falar do declínio da função paterna determinando organizações discursivas de caráter obsessivo como também montagens perversas evidentes no laço social.

Assim, observamos formas atuais de exercício da feminilidade, como da virilidade, da procriação, da relação com as crianças, etc., estimuladas pela pretensão científica e fundamentalmente técnica de eclipse do sujeito no apelo a uma racionalidade que opera como resposta ao "nâo saber".

Exemplifica essa tendência a freqüência na clínica psicanalítica da presença de mulheres obsessivas, campo geralmente reservado aos homens. Lembramos que no começo do século passado FREUD inaugurou a psicanálise escutando as histéricas sendo justamente aí que se apresentou a ele a torção de uma histeria para uma obsessão feminina.

Vocês verão as implicações desta mudança.

Trata-se de uma mulher que demanda análise em função de uma "histeria de angustia pura e simples", ${ }^{1}$ porém que de um dia para outro mudou para uma neurose obsessiva das mais graves. Este "bilingüismo" instiga FREUD em relação ao problema da "escolha de neurose" passando a nos relatar os eventos que teriam determinado tal percurso.

Escutemos FREUD: "Até contrair a doença a paciente tinha sido uma esposa feliz, satisfeita quase plenamente. Seu desejo de ter filhos respondia a uma fixação do desejo infantil, e adoeceu quando soube que não poderia dar ao homem a

1. FREUD, Sigmund. Obras Completas - La predisposición a laneurose obsesiva. Vol. XII, Buenos Aires: Amorrortu Editores 1990, 1913. 
quem amava com exclusividade ... Fazia tudo para não deixar ver a seu maridoq̨ue ela havia adoecido em conseqüência da frustração por ele determinada.

O marido compreendeu sem que mediara confissão nem declaração, que significava a angústia de sua esposa, mor. tificou-se por isso sem demonstrá-lo e pela sua vez reagiu neuroticamente dene. gando-se, por vez primeira, o comércio sexual ... A muiher acreditou na sua im. potência permanente e produziu os primeiros sintomas obsessivos. Oconteúdo de sua obsessão era uma penosa compulsão a lavar-se e à limpeza, acompanhada de medidas protetoras, de extrema energia, frente a daninhas influências que outros teriam a temer dela".

Ou seja, a impotência do outro, seu parceiro desencadeia a neurose obsessiva, primeiro ponto a partir do qual tentarei extrair algumas direções, centrando o laço conjugal no domínio da modernidade.

Lembremos que desde o início do séciulo pasassado até algumas décadas atrás, a histeria era paradigmática de um interrogante que concernia a ambos os sexos, e que se expressava na seguinte interrogação: que quer uma mulher?

Mas por scr este um enigma que corresponde a ordem do desejo inconsciente não deixa de situar o objeto e sua falta, só restando o paradoxo de responder reiterando a pergunta, porque "o saber" paterno a quem esse interrogante é endereçado é só uma suposição.

No final do século estamos novamente frente ao "bilingüismo" freudiano: ele se observa na clínica, através de fenômenos variados, expressão de sentimentos de impotência enquanto fragilidade imaginária. Simultaneamente, e de maneira denegatória, opera uma injunção, eco do âmbito social, de potência sem limites, eficiente.

As pessoas sāo tomadas por esta injunção já que o reconhecimento que se espera do outro opera como signo de talento pessoal.

Eficiência que estando adscrita à perfeição fálica testemunha do imperativo social.

Se a histérica falava a viva voz através de um corpo desenhado pelas palavras, os quadros obsessivos expressam a submissão voluntária à ordem da necessidade e conseqüentemente ao apagamento do desejo, sincronia que mostra como a questão sobre a virilidade é colocada num fundo de impotência fálica.

Não esquecer que vivemos nos tempos do viagra e companhia, remédio ao alcance da mão para a "devida" impotência.

Nestas circunstâncias o pai que comparece no sintoma é um pai incastrado, totêmico, potente, sem limites, sustentado pelos filhos sacrificados na sua devoção.

Continuemos mais um passo escutando agora FREUD no seu trabalho sobre 0 inconsciente. ${ }^{2}$

Ele disse: "Não sem boas razões, tenho sustentado que todo homem possui no seu inconsciente instrumentos com os quais é capaz de interpretar as exteriorizaçōes do inconsciente em outro".

2. FAEUD, Sigmund. Obras Completas - O inconsciente. Vol. XIV, 1915, p. 191. 
Parafraseando FREUD, dizemos que todo homem é capaz de interpretar os significantes do Outro, do Outro Social e assim produzir sintomas que são a expres. são do declínio da função paterna, da função paterna enquanto garante terceiro.

Não podemos evitar, padecemos dos significantes que circulam na cultura. Assim sendo, a nova economia de mercado aliada à tecnologia de informação constituem os alicerces do Admirável Mundo Novo.

Permitam-me ilustrar um pouco mais essa problemática com uma reflexão inquietante de IGNACIO RAMONET, de Le Monde Diplomatique, ${ }^{3}$ ele disse:

"Temos vocação a substituir o cérebro, o computador está em vias de provocar, ante nossos olhos, mutações ainda mais formidáveis e inéditas. Cada um constata em efeito, que há toda uma mudança em torno de si mesmo: o contexto econômico, os dons políticos, os parâmctros ecológicos, os valores sociais, os critérios culturais e as atitudes individuais."

Como podemos ver de olhos arregaladamente fechados estamos imersos em mudanças vertiginosas, sub-repticiamente invasoras e de uma potência totalitária de tal magnitude que não raro anulam nosso discernimento.

O caso clínico e a realidade social evocada têm consistência porque o privado e o público não são campos alheios, pelo contrário, os significantes culturais permeiam as singularidades.
Por essa razão podemos articular sintomas sociais e sintomas pessoais.

Voltemos ao caso clínico freudiano para verificar a lógica que o fundamenta $\mathrm{e}$ nos servir dela na leitura de fenômenos sociais atuais.

Para lembrar, trata-se de um sintoma ligado à falha da potência viril para concepção de unı filho. Mas o que observarmos nos dias de hoje naquilo que concerne a procriação? Uma vez mais a oferta produz demanda. A ciência e a tecnologia ao serviço da ordem médica, quando se trata de aceder a maternidade ou a paternidade, silencia ou anula a dimensão da troca simbólica. O Dom cede seu lugar ao Bem. Bem de quem? Do triunfo da técnica como apresenta CONTARDO CALLIGARIS 4 e prossegue: "da instrumentalidade, só é triunfo na medida que os homens mesmos funcionem como parte integrante desta técnica, quer dizer funcionem como instrumentos".

Porém teríamos que nos perguntar por que os seres humanos consentiriam em reduzir a própria subjetividade a uma instrumentalidade. Qual é a ordem que vigora nestas estruturas? Ou para dizer de outro modo, qual é o pai que comparece nesses discursos?

Se temos em conta a complexidade do querer e do desejo no humano, podemos nos aproximar aos entraves desta "paixão pela instrumentalidade".

3. RAMONET, Ignacio. "La Nouvelle Economie". In Le Monde Diplomatique.

4. CALLIGARIS, Contardo. A sedução totalitária - clínica da social. Săo Paulo: Escuta, 1991. 
Na medicina da procriação fica silenciada pela ordem médica o dizer dos sujeitos, de seu desejo de filho para a mulher e para o homem enquanto mãe e pai, do Dom que cada um oferece ao outro, se transformado no Bem, que a medicina faz entrar rapidamente nas estatísticas dos sucessos e fracassos nesta operação que era para ser a expressão de uma menage a trois: Ela, ele e esse espírito misterioso que a psicanálise chama de Pai simbólico, e se transforma numa menage a Deux: Um, construído pela equipe médica e seus endeusados aparelhos, e Outro o casal tomado como se fosse Um.

Como vocês sabem o efeito de toda relação dual é a de ser especular, imaginária e produzir laços onde impera desconfiança, exclusão, agressấo, ou seja, que eles têm um caráter paranóico onde cada um sente-se prejudicado por aquilo que lhe teria sido roubado, lesado pelo outro que não "soube" corresponder à expectativa do esperado.

Não é também a posição do casal na sua exigência de felicidade?

Uma paciente me dizia enquanto chorava pelo seu infortúnio: "Eu só queria ser feliz!” Tem razão em se lamentar, já que na medida em que a felicidade se tornou um fator de política, como apontava SAINT JUST, porque não reclamar que a distribuição não foi eqüitativa? "Felicidade para o maiornúmero de pessoas pregam uns. Direito a ser feliz, clamam outros, frases ingênuas com que iludem "inocentes"”.

Por outro lado, se tratando de mudanças no casal, claro que tem havido uma evolução, porém não parece que tenha havido o que podemos chamar de progresso no laç̧o discursivo. Pelo contrário, conside- rando-se o modelo de início de século, que FREUD também retrata em vários textos, observamos que as expectativas dos cônjuges eram durabilidade, fecundidade e transmissão, sendo acrescida das paixões do laço extraconjugal: diversidade e intensidade.

Enquanto hoje, na lógica do "nada a perder" no exercício dos encontros sexuais, amor e desejo sexual para o casal vemos, o recurso a contracepção sofrer o abalo da AIDS, as adolescentes mesmo com estas condições não deixam de engendrar filhos indesejados, aumentando o número de abortos de riscos ou de crianças semiabandonadas, ou acolhidas no meio familiar configurando estranhas idéias de maternidade, paternidade e filiação, desde que essas crianças muitas vezes são sustentadas afetiva e financeiramente pelos avôs. Como se os filhos abortados, "programados" ou recusados pela pílula retornassem nos netos "reparadores". Taivez uma forma de os filhos interrogarem pais-avôs sobre o desejo materno-paterno em relação a si rnesmos.

Bom, por não dizer que não falei de ilusão, idílio e poesia dos encontros no casal 2000 , vale a pena considerar o que não se deixa de recomendar frente às mazelas do leito doméstico. "Há que falar, falando a gente se entende".

Já passam 70 anos que FREUD nos transmitiu mais uma descoberta sua. Tratase do mal-estar na civilização, repousando na insatisfação sexual. Então vemos que infelizmente não somos bons em comunicação, malgrando as tentativas reiteradas, devemos reconhecer a impossibilidade imanente ao seguinte paradoxo: expresso no aforismo lacaniano geralmente mal compre- 
endido que disse: "Não há relação sexual". Há relação de sexos, sim, mas esta não é complementar.

A clínica testemunha disso diariamente pelo simples fato de que o que anima a vida sexual é uma particular organização chamada pela psicanálise de fantasma, que além de ser singular, é diferente para os dois sexos. Isto quer dizer que quando se persegue no encontro amoroso gozar de um mesmo objeto, este por razões de estrutura e não por má vontade dos parceiros resiste a fazer de dois corpos um, instância almejada enquanto protótipo de uma satisfação plena. Então, longe de produzir uma feliz completariedade, temos a discórdia dos sexos. Nada a perder, todo a perder!

Se acrescentarmos à vida sexual do casal a expectativa de felicidade no matrimônio, traduzido em companheirismo, cumplicidade, liberdade, respeito, confiança, sinceridade, vemos que estamos frente a uma injunção impossível.

Será necessário, então, fazer o Luto com maiúscula para evocar a Lei do desejo, também com maiúscula, o que não deixa de ser extremamente difícil no contexto social atual, no qual a invasora economia de mercado, a prevalência do pensamento único, o papel da imagem em detrimento da palavra, por mencionar só alguns, transformaram os sujeitos em objetos da rede globai.

Contrariamente o objeto do desejo sempre escapa por razões de evidência clínica e teórica, já que é próprio do desejo não atingir seu objeto porque ele não há. Só poderá brilhar alhures no território de uma miragem impossível.

Ética e laço conjugal é um tenıa que resiste a conclusões, por isso acredito mais na reformulação dos interrogantes que demarcam para cada um, via significante, os impasses da servidão consentida neste novo tempo de escravidão ou a coragem dos sujeitos ao assumir sua condiçāo ética desejante.

Trabalho apresentado no $1^{\circ}$ Encontro Sul-Brasileiro de Psicanálise, de 24 a 27 de agosto de 2000

\section{Bibliografia}

CALLIGARIS, Contardo. A sedução totalitária Clínica do social. São Paulo: Escuta, 1991.

FREUD, Sigmund. Obras Completas - La predisposición a la neurose obsesiva. Vol. XII, Buenos Aires: Amorrortu Editores 1990, 1913.

Obras completas - O inconsciente. Vol. XIV, 1915, p. 191.

RAMONET, Ignacio. "La Nouvelle Economie". In Le Monde Diplomatique. 